\title{
Optimization of drying the semi-dried lamb meat product (jerky)
}

Trinh A. Nguyen*, Thao T. T. Nguyen, \& Linh T. Le

Faculty of Food Science and Technology, Nong Lam University, Ho Chi Minh City, Vietnam

\author{
ARTICLE INFO \\ Research Paper \\ Received: December 17, 2018 \\ Revised: May 27, 2019 \\ Accepted: July 22, 2019 \\ Keywords \\ Lamb jerky \\ Lamb meat \\ Semi-dried food \\ Semi-dried lamb meat

\section{* Corresponding author} \\ Nguyen Anh Trinh \\ Email: natrinh@hcmuaf.edu.vn
}

\begin{abstract}
Convection drying was used to investigate the drying process of semi-dried lamb. The drying conditions were carried in combination of adding sorbitol and glycerin and salt. The results showed that the most appropriate drying conditions were at temperature of $56^{0} \mathrm{C}$, drying time of $210 \mathrm{~min}$ and wind speed of $0.24 \mathrm{~m} / \mathrm{s}$. The addition of sorbitol, glycerin, common salt in product was $4.37 \%, 1.93 \%$, and $3.4 \%$, respectively which were suitable for maintaining the aw of the product at $0.67 \mathrm{~g}$.
\end{abstract}

Cited as: Nguyen, T. A., Nguyen, T. T. T., \& Le, L. T. (2019). Optimization of drying the semi-dried lamb meat product (jerky). The Journal of Agriculture and Development 18(4), 90-98. 


\title{
Tối ưu hóa quá trình sấy sản phẩm thịt cừu sấy dẻo
}

\author{
Nguyễn Anh Trinh*, Nguyễn Thị Thanh Thảo \& Lê Trúc Linh \\ Khoa Công Nghệ Thực Phẩm, Trường Đại Học Nông Lâm TP.HCM, TP. Hồ Chí Minh
}

\section{THÔNG TIN BÀI BÁO}

Bài báo khoa học

Ngày nhận: 17/12/2018

Ngày chỉnh sửa: $27 / 05 / 2019$

Ngày chấp nhận: 22/07/2019

\section{Từ khóa}

Jerky cừu

Thịt cừu

Thịt cừu sấy dẻo

Thực phẩm sấy dẻo

*Tác giả liên hệ

Nguyễn Anh Trinh

Email: natrinh@hcmuaf.edu.vn

\section{TÓM TẮT}

Máy sấy khay theo nguyên tắc đối lưu là dùng tác nhân sấy làm ẩm trong sản phẩm bay hơi và thoát ra ngoài. Mỗi sản phẩm thực phẩm có thành phần nguyên vật liệu, cấu trúc,... khác nhau nên phải có chế độ sấy phù hợp. Ngoài ra, sorbitol, glycerin và muối ăn là những thành phần ngoài tính chất tạo vị, còn có khả năng giữ ẩm cho sản phẩm. Bổ sung sorbitol, glycerin và muối ăn trong các sản phẩm sấy có vai trò quan trọng trong việc hạ hoạt độ nước (aw) của sản phẩm, rút ngắn được thời gian sấy. Mục tiêu của nghiên cứu này là nhằm xác định thông số kỹ thuật tối ưu của quá trình sấy cho qui trình sản xuất sản phẩm thịt cừu sấy dẻo (jerky). Kết quả nghiên cứu đã xác định được chế độ sấy tối ưu ở nhiệt độ $56^{0} \mathrm{C}$ trong 210 phút với tốc độ gió là $0,24 \mathrm{~m} /$ giây. Tỷ lệ tối ưu của sorbitol, glycerin, muối ăn trong sản phẩm là $4,37 \%$ sorbitol, $1,93 \%$ glycerin và $3,4 \%$ muối ăn, sản phẩm có aw là 0,67 .

\section{1. Đặt Vấn Đề}

Sấy là một trong những phương pháp dùng để bảo quản thực phẩm, được thực hiện từ lâu đời, là phương pháp dùng nhiệt làm giảm độ ẩm của sản phẩm đến một mức độ an toàn cho việc lưu trữ và vận chuyển, làm bất hoạt các hoạt động của vi sinh vật (Law \& ctv., 2014). Sấy đối lưu là phương pháp dùng luồng không khí sấy với nhiệt độ, độ ẩm và tốc độ gió phù hợp, sẽ làm ẩm trong sản phẩm bay hơi và thoát ra ngoài, là quá trình khuếch tán do chênh lệch ẩm ở bề mặt và bên trong vật liệu hay do chênh lệch áp suất hơi riêng phần ở bề mặt vật liệu và môi trường xung quanh (Nindo \& Tang, 2007). Tốc độ gió là nhân tố ảnh hưởng lớn đến quá trình làm khô. Tốc độ chuyển động của không khí quá lớn sẽ khó giữ được nhiệt lượng trên nguyên liệu sấy, còn tốc độ chuyển động của không khí quá nhỏ sẽ làm chậm quá trình làm khô của nguyên liệu dẫn đến hư hỏng sản phẩm (Aranda \& ctv., 2010).

Mỗi sản phẩm thực phẩm có thành phần nguyên vật liệu, cấu trúc, ... khác nhau nên phải có chế độ sấy phù hợp. Sorbitol, glycerin và muối ăn là những thành phần ngoài vai trò tạo vị còn có khả năng giữ ẩm cho sản phẩm, nhờ vào khả năng liên kết với nước và từ đó có ảnh hưởng đến hoạt độ nước (aw) (Nguyen \& Tran, 2016), sự hiện diện của $\mathrm{NaCl}$ ảnh hưởng đến kết cấu, khả năng giữ nước, điểm đẳng điện và chức năng protein (Gallart-Jornet \& ctv., 2007).

Việc bổ sung sorbitol, glycerin và muối ăn trong các sản phẩm sấy có vai trò quan trọng trong việc rút ngắn được thời gian sấy nhờ vào khả năng làm biến tính protein, tạo cấu trúc chặt chẽ hơn và làm giảm lượng nước tự do trong sản phẩm. Tuy nhiên, việc sử dụng sorbitol, glycerin và muối ăn trong thực phẩm có giá trị giới hạn, việc bổ sung ở nồng độ quá cao thường làm thay đổi vị, ảnh hưởng đến giá trị cảm quan của sản phẩm, (Nguyen \& Tran, 2016). Kết hợp các thành phần chất tan khác nhau nhằm hạ giá trị aw của sản phẩm đến mức mong muốn cần được quan tâm. Mức độ giảm aw của sản phẩm còn phụ thuộc vào đặc tính tan, khả năng liên kết tối đa của chất tan và nước trong thực phẩm, chính vì thế, đối 
với từng loại sản phẩm, việc khảo sát nhằm tìm ra hàm lượng bổ sung phù hợp nhằm hạ hoạt độ nước của sản phẩm đến mức mong muốn hay giá trị thấp nhất cần phải được khảo sát.

\section{Vật Liệu và Phương Pháp Nghiên Cứu}

Nguyên liệu thịt cừu được cung cấp bởi cơ sở sản xuất thịt dê cừu Triệu Tín - quốc lộ $1 \mathrm{~A}$, ngã 3 Phước Khánh, Ninh Phước, Ninh Thuận. Chúng tôi tiến hành thí nghiệm và xác định được tỉ lệ nguyên vật liệu, thành phần gia vị cho sản phẩm thịt cừu sấy dẻo theo qui trình chế biến dự kiến. Kết quả này được giữ cố định cho tất cả các nghiệm thức của thí nghiệm tối ưu hóa quá trình sấy.

Chúng tôi sử dụng máy sấy khay có các khay sấy được đặt vào giá cố định bên trong buồng sây, đóng kín buồng sấy và đưa luồng không khí sấy vào để tiếp xúc với sản phẩm sấy. Dòng không khí sấy song song với mặt phẳng của các khay sấy (ngang khay). Sau một thời gian sấy, độ ẩm của sản phẩm được giảm đến độ ẩm yêu cầu thì dừng hoạt động, mở cửa buồng và lây tất cả các khay với sản phẩm sấy ra ngoài.

2.1. Thí nghiệm tối ưu hóa chế độ sấy sản phẩm thịt cừu sấy dẻo

\subsubsection{Thí nghiệm xác định phạm vi giới hạn của nhiệt độ sấy và thời gian sấy}

Tiến hành sấy sản phẩm ở 3 nhiệt độ $50^{\circ} \mathrm{C}$, $55^{\circ} \mathrm{C}$ và $60^{\circ} \mathrm{C}$ (Flath \& Diana, 1985). Sau mỗi 30 phút sấy, phân tích ẩm độ và đánh giá cảm quan sản phẩm để sơ bộ xác định nhiệt độ và thời gian sấy thích hợp cho sản phẩm thịt cừu sấy dẻo. Kết quả ghi nhận là giá trị trung bình của 3 lần lặp lại.

\subsubsection{Xác định phạm vi giới hạn của tốc độ gió khi sấy}

Tham khảo tài liệu (Aranda \& ctv., 2010), chúng tôi xác định phạm vi giới hạn của tốc độ gió để sấy sản phẩm thịt cừu sấy dẻo.

\subsubsection{Thí nghiệm xác định chế độ sấy tối ưu tối ưu}

Chúng tôi đã thực hiện bố trí thí nghiệm theo phương pháp bề mặt đáp ứng (Responese Surface Design), Box- Behnken (BDD) với 3 yếu tố khảo sát là nhiệt độ sấy $\mathrm{x}_{1}$, tốc độ gió $\mathrm{x}_{2}$ và thời gian sấy $x_{3}$. Trên cơ sở xác định $x_{1}, x_{2}, x_{3}$ xây dựng phương trình hồi quy thực nghiệm để mô tả sự phụ thuộc của 3 yếu tố khảo sát lên các chỉ tiêu theo dõi. Từ đó chọn ra các mức thích hợp của các yếu tố khảo sát cho quá trình sấy. Phương trình bậc 2 có dạng: $\mathrm{Y}=\mathrm{a}_{0}+\mathrm{a}_{1} \mathrm{x}_{1}+\mathrm{a}_{2} \mathrm{x}_{2}+$ $a_{3} x_{3}+b_{1} x_{1} x_{2}+b_{2} x_{1} x_{3}+b_{3} x_{2} x_{3}+c_{1} x_{1}^{2}+c_{2} x_{2}^{2}$ $+\mathrm{c}_{3} \mathrm{x}_{3}^{2}$ với $\mathrm{y}$ là độ ẩm sản phẩm $(\%)$.

\subsection{Thí nghiệm tối ưu hóa tỷ lệ sorbitol, glyc- erin, muối ăn}

\subsubsection{Thí nghiệm xác định phạm vi giới hạn tỷ lệ sorbitol}

Tiến hành chế biến sản phẩm thịt cừu sấy dẻo với tỷ lệ sorbitol khác nhau $(0 \%, 3 \%, 4 \%, 5 \%)$ (Nguyen \& Tran, 2016). Sau mỗi 30 phút sấy, phân tích ẩm độ và đánh giá cảm quan sản phẩm để sơ bộ xác định giới hạn của tỷ lệ sorbitol thích hợp cho sản phẩm thịt cừu sấy dẻo.

\subsubsection{Xác định phạm vi giới hạn của tỷ lệ glycerin}

Tiến hành chế biến sản phẩm thịt cừu sấy dẻo với tỷ lệ glycerin khác nhau $(0 \%, 1 \%, 2 \%, 3 \%)$ (Nguyen \& Tran, 2016). Sau mỗi 30 phút sấy, phân tích ẩm độ và đánh giá cảm quan sản phẩm để sơ bộ xác định giới hạn của tỷ lệ glycerin thích hợp cho sản phẩm thịt cừu sấy dẻo.

\subsubsection{Xác định phạm vi giới hạn của tỷ lệ muối ăn}

Chúng tôi tiến hành thí nghiệm xác định thành phần gia vị cho sản phẩm thịt cừu sấy dẻo theo qui trình chế biến dự kiến để xác định giới hạn của tỷ lệ muối ăn thích hợp cho sản phẩm thịt cừu sấy dẻo.

\subsubsection{Thí nghiệm tối ưu hóa tỷ lệ sorbitol, glyc- erin, muối ăn}

Chúng tôi đã thực hiện bố trí thí nghiệm theo phương pháp bề mặt đáp ứng (Responese Surface Design), Box- Behnken (BDD) với 3 yếu tố khảo sát là tỷ lệ sorbitol $\mathrm{x}_{1}$, tỷ lệ glycerin $\mathrm{x}_{2}$ và tỷ lệ muối ăn $\mathrm{x}_{3}$. Trên cơ sở xác định $\mathrm{x}_{1}, \mathrm{x}_{2}, \mathrm{x}_{3}$ xây dựng phương trình hồi quy thực nghiệm để mô tả sự phụ thuộc của 3 yếu tố khảo sát lên các chỉ tiêu theo dõi. Từ đó chọn ra các mức thích hợp của các yếu tố khảo sát cho quá trình sấy. Phương trình bậc 2 có dạng: $\mathrm{Y}=\mathrm{a}_{0}+\mathrm{a}_{1} \mathrm{x}_{1}+$ $a_{2} x_{2}+a_{3} x_{3}+b_{1} x_{1} x_{2}+b_{2} x_{1} x_{3}+b_{3} x_{2} x_{3}+c_{1} x_{1}^{2}$ $+\mathrm{c}_{2} \mathrm{x}_{2}^{2}+\mathrm{c}_{3} \mathrm{x}_{3}^{2}$ với $\mathrm{y}$ là độ ẩm sản phẩm $(\%)$. 


\section{Kết quả và Thảo luận}

Theo kết quả của thí nghiệm, chúng tôi có được thành phần và tỷ lệ của nguyên vật liệu, gia vị, phụ gia cho sản phẩm thịt cừu sấy dẻo được giữ cố định cho tất cả các nghiệm thức của thí nghiệm tối ưu hóa quá trình sấy là thịt cừu, mỡ heo, bột hương liệu, tinh bột, gia vị,...

\subsection{Thí nghiệm tối ưu hóa chế độ sấy sản phẩm thịt cừu sấy dẻo}

\subsubsection{Thí nghiệm xác định phạm vi giới hạn của nhiệt độ sấy và thời gian sấy}

Biến thiên ẩm độ của sản phẩm thịt cừu sấy dẻo theo thời gian sấy ứng với nhiệt độ sấy khác nhau được thể hiện ở Hình 1.

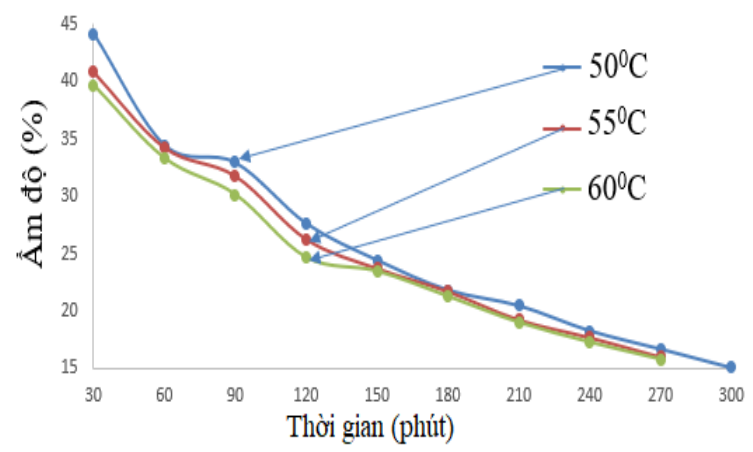

Hình 1. Ảnh hưởng của nhiệt độ, thời gian sấy đến thay đổi ẩm độ của sản phẩm.

Kết quả nghiên cứu cho thấy ở cùng tốc độ gió thì nhiệt độ sấy càng cao thì thời gian sấy càng ngắn, điều này cũng được kết luận trong các nghiên cứu của các tác giả Prachayawarakorn \& ctv. (2002); Djendoubi \& ctv. (2009). Quá trình sấy làm độ ẩm của sản phẩm giảm do nước trong nguyên liệu di chuyển từ trong ra ngoài, ở nhiệt độ càng cao nước trong nguyên liệu thoát ra càng nhanh (Ortiz \& ctv., 2013). Nhiệt độ sấy gây biến tính các protein đã được nghiên cứu từ 40 đến $80^{\circ} \mathrm{C}$ (Ofstad \& ctv., 1996), trong khoảng nhiệt độ sấy này, sản phẩm bị giảm độ ẩm, từ đó gây ra biến tính của protein sợi cơ và sự mất nước trong sản phẩm.

Kết quả khảo sát cho thấy trong thời gian sấy từ 180 đến 240 phút ứng với phạm vi nhiệt độ $50^{\circ} \mathrm{C}$ đến $60^{\circ} \mathrm{C}$, ẩm độ của sản phẩm dao động trong khoảng $20 \%$ và kết quả đánh giá cảm quan sản phẩm cừu sấy dẻo cho thấy những mẫu trong phạm vi sấy 180 đến 240 phút cho sản phẩm được nhiều người ưa thích, có cấu trúc mềm dẻo, màu đẹp.

Theo kết quả trên, chúng tôi chọn phạm vi giới hạn nhiệt độ sấy từ $50^{\circ} \mathrm{C}$ đến $60^{\circ} \mathrm{C}$ và thời gian sấy từ 180 phút đến 240 phút để thực hiện thí nghiệm tối ưu hóa.

\subsubsection{Xác định phạm vi giới hạn của tốc độ gió khi sây}

Qua một số thí nghiệm nghiên cứu của chúng tôi liên quan đến tốc độ gió khi sấy trên nguyên liệu thịt heo, thịt bò và thủy sản, kết hợp tham khảo tài liệu (Aranda \& ctv., 2010), chúng tôi chọn tốc độ gió để sấy sản phẩm thịt cừu sấy dẻo là $0,21 \mathrm{~m} /$ giây, $0,24 \mathrm{~m} /$ giây và $0,27 \mathrm{~m} /$ giây.

\subsubsection{Thí nghiệm xác định chế độ sấy tối ưu}

Từ các thí nghiệm xác định phạm vi ảnh hưởng của các yếu tố thí nghiệm, giá trị mã hóa và ma trận của thí nghiệm tối ưu chế độ sấy được thể hiện trong Bảng 1 và 2.

Bảng 1. Giá trị mã hóa các thông số thí nghiệm tối ưu quá trình sấy

\begin{tabular}{lccc}
\hline \multirow{2}{*}{ Biến độc lập } & \multicolumn{3}{c}{ Giá trị mã hóa } \\
\cline { 2 - 4 } & -1 & 0 & 1 \\
\hline $\mathrm{x}_{1}$ : Nhiệt độ sấy $\left({ }^{0} \mathrm{C}\right)$ & 50 & 55 & 60 \\
$\mathrm{x}_{2}$ : Tốc độ gió $(\mathrm{m} /$ giây) & 0,21 & 0,24 & 0,27 \\
$\mathrm{x}_{3}$ : Thời gian sây (phút) & 180 & 210 & 240 \\
\hline
\end{tabular}

Kết quả thu được từ 15 thí nghiệm đã được xử lý bằng phần mềm thống kê JMP, từ đó xác định được mối tương quan giữa các yếu tố nhiệt độ sấy, tốc độ gió, thời gian sấy với độ ẩm của sản phẩm, đồng thời xây dựng được phương trình hồi quy và dự đoán các thông số của các yếu tố cho độ ẩm tối ưu. Sự tương quan giữa độ ẩm mô hình và độ ẩm thực tế được thể hiện trong Hình 2.

Giá trị $\mathrm{R}^{2}$ của mô hình là 0,95 ; cho thấy độ ẩm thực tế và độ ẩm mô hình có sự tương quan với nhau. Chúng tôi kết luận là phương trình hồi quy có mức độ tương thích khá cao, ở độ tin cậy 95\%. Qua xử lý thống kê, cho thấy tác động của nhiệt độ, thời gian có ảnh hưởng quan trọng đến độ ẩm của sản phẩm có và có ý nghĩa thống kê $(P$ $<0,05)$. Sau khi loại bỏ những yếu tố không có ảnh hưởng quan trọng, chúng tôi có được phương trình hồi quy: $\mathrm{y}=16,663-0,87 \mathrm{x}_{1}-0,6675 \mathrm{x}_{1} \mathrm{x}_{3}$. Trong đó $\mathrm{y}$ là độ ẩm của sản phẩm $(\%), \mathrm{x}_{1}$ (nhiệt độ sấy) và $\mathrm{x}_{3}$ (thời gian sấy). 
Bảng 2. Ma trận của thí nghiệm tối ưu quá trình sấy

\begin{tabular}{cccccc}
\hline TT & Ma trận & Nhiệt độ sấy $\left({ }^{0} \mathrm{C}\right)$ & Tốc độ gió $(\mathrm{m} /$ giây) & Thời gian sấy (phút) & Độ ẩm $(\%)$ \\
\hline 1 & $0--$ & 55 & 0,21 & 180 & 16,28 \\
2 & $0+-$ & 55 & 0,21 & 240 & 16,81 \\
3 & $0-+$ & 55 & 0,27 & 180 & 16,46 \\
4 & 0 & 60 & 0,24 & 240 & 15,15 \\
5 & $-0-$ & 50 & 0,21 & 210 & 17,95 \\
6 & --0 & 50 & 0,24 & 180 & 16,45 \\
7 & 0 & 55 & 0,24 & 210 & 16,47 \\
8 & +-0 & 60 & 0,24 & 180 & 16,41 \\
9 & $+0-$ & 60 & 0,21 & 210 & 15,54 \\
10 & -+0 & 50 & 0,24 & 240 & 17,86 \\
11 & $-0+$ & 50 & 0,27 & 210 & 17,69 \\
12 & 0 & 55 & 0,24 & 210 & 16,55 \\
13 & $+0+$ & 60 & 0,27 & 210 & 15,89 \\
14 & $0++$ & 55 & 0,27 & 240 & 16,49 \\
15 & 0 & 55 & 0,24 & 210 & 16,97 \\
\hline
\end{tabular}

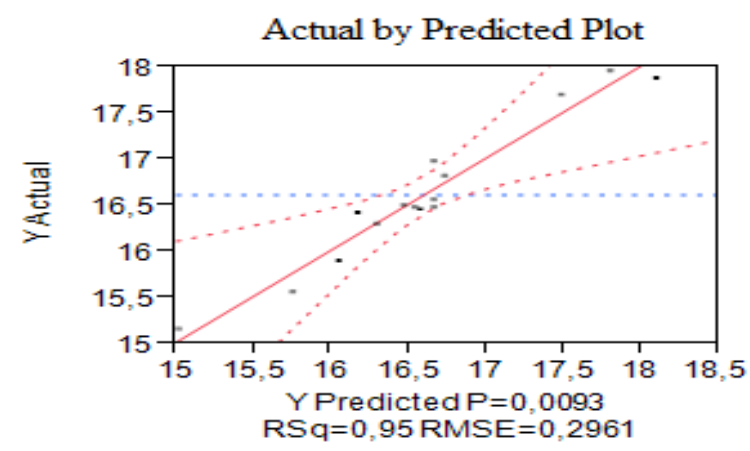

Hình 2. Biểu đồ thể hiện sự tương quan giữa độ ẩm mô hình và độ ẩm thực tế.

Mô hình xác định được cho thấy độ ẩm của sản phẩm nghịch biến với nhiệt độ sấy, với tương tác giữa nhiệt độ sấy và thời gian sây, điều này được giải thích khi sấy càng lâu sẽ làm ức chế sự khô của sản phẩm do hình thành của một lớp vỏ protein trên bề mặt gây ra sự khô cứng bề mặt dẫn đến càng sấy ở nhiệt độ cao và thời gian sấy lâu sẽ làm nước trong sản phẩm thoát ra chậm hơn ban đầu (Jittinandana \& ctv., 2002).

Dự đoán giá trị tối ưu của các yếu tố thí nghiệm: Sự tương tác của các yếu tố khảo sát của chế độ sấy được biểu diễn qua đường đồng mức được thể hiện ở Hình 3. Chúng tôi chọn được các thông số sấy tối ưu: nhiệt độ sấy $56^{0} \mathrm{C}$, tốc độ gió $0,24 \mathrm{~m} /$ giây và thời gian sấy 209 phút thì độ ẩm của sản phẩm là $16,5 \%$.

Kiểm chứng giá trị tối ưu từ mô hình thực nghiệm: Từ các thông số tối ưu của chế độ sấy

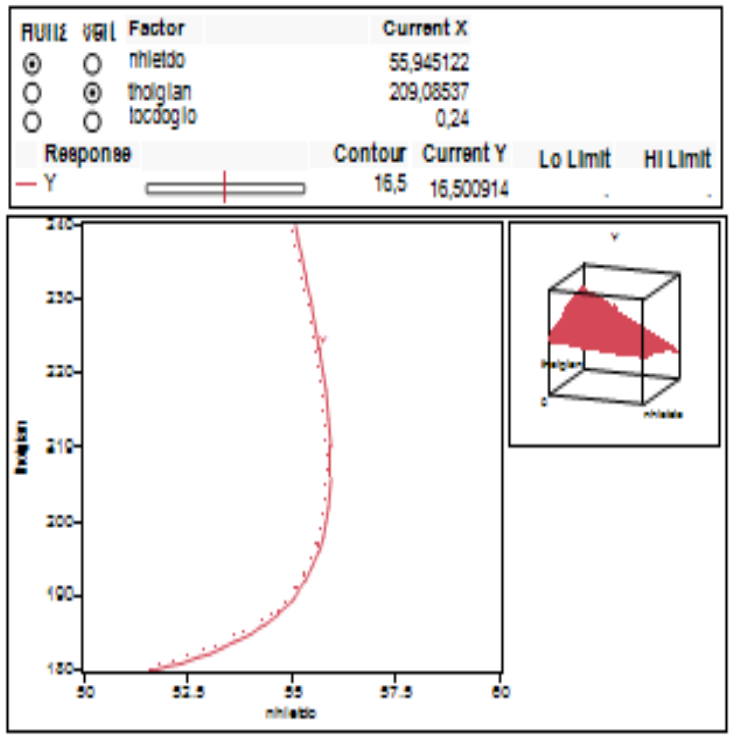

Hình 3. Đường đồng mức biểu diễn tương quan giữa độ ẩm và chế độ sấy.

sản phẩm thịt cừu sấy dẻo được xác định bằng phương trình của mô hình bề mặt đáp ứng, chúng tôi tiến hành thực nghiệm để kiểm chứng lại các thông số tối ưu, chứng minh tính xác thực của mô hình. Chúng tôi thực nghiệm trên các thông số tối ưu với 3 lần lặp lại, lấy giá trị trung bình, kết quả được trình bày ở Bảng 3 và 4 .

Kết quả cho thấy độ ẩm sản phẩm thịt cừu sấy dẻo có sự khác biệt giữa mô hình và thực tế là $1,19 \%$ nhỏ hơn $5 \%$, nên mô hình có giá trị thực tiễn và có thể áp dụng vào thực tế sản xuất. 
Bảng 3. Kết quả kiểm chứng giá trị độ ẩm thực nghiệm của quá trình sấy thịt cừu

\begin{tabular}{cc}
\hline Tham số thống kê & $\begin{array}{c}\text { Độ ẩm sản phẩm thực } \\
\text { tế }(\%)\end{array}$ \\
\hline 1 & 16,49 \\
2 & 16,17 \\
3 & 16,25 \\
Độ ẩm trung bình & 16,30 \\
SD & 0,17 \\
\hline
\end{tabular}

Bảng 4. Kiểm chứng giá trị tối ưu từ mô hình bằng thực nghiệm

\begin{tabular}{ccc}
\hline \multirow{2}{*}{ Tham số thống kê } & \multicolumn{2}{c}{ Điều kiện } \\
\cline { 2 - 3 } & Mô hình & Thực tế \\
\hline Độ ẩm sản phẩm (\%) & 16,50 & 16,30 \\
Độ lệch chuẩn (SD) & 0 & 0,17 \\
\hline
\end{tabular}

Chúng tôi chọn chế độ sấy áp dụng vào sản xuất là: nhiệt độ sấy $56^{0} \mathrm{C}$, thời gian sấy 210 phút, tốc độ gió $0,24 \mathrm{~m} /$ giây.

\subsection{Thí nghiệm tối ưu hóa tỷ lệ sorbitol, glyc- erin, muối ăn}

\subsubsection{Thí nghiệm xác định phạm vi giới hạn tỷ lệ sorbitol}

Biến thiên ẩm độ của sản phẩm thịt cừu sấy dẻo theo thời gian sấy ứng với tỷ lệ sorbitol khác nhau được thể hiện ở Hình 4.

Kết quả đánh giá cảm quan sản phẩm ứng với mỗi 30 phút sấy cho thấy đa số mẫu trong phạm vi tỷ lệ sorbitol $4 \%$ cho sản phẩm được nhiều người ưa thích, có cấu trúc mềm dẻo.

Theo kết quả trên, chúng tôi chọn phạm vi giới hạn tỷ lệ sorbitol từ $3,5 \%$ đến $4,5 \%$ để thực hiện thí nghiệm tối ưu hóa.

\subsubsection{Xác định phạm vi giới hạn của tỷ lệ glycerin}

Biến thiên ẩm độ của sản phẩm thịt cừu sấy dẻo theo thời gian sấy ứng với tỷ lệ glycerin khác nhau được thể hiện ở Hình 5.

Kết quả đánh giá cảm quan sản phẩm ứng với mỗi 30 phút sấy cho thấy đa số mẫu trong phạm vi tỷ lệ glycerin $2 \%$ cho sản phẩm được nhiều người ưa thích, có cấu trúc mềm dẻo.

Theo kết quả trên, chúng tôi chọn phạm vi giới hạn tỷ lệ glycerin từ 1,5\% đến $2,5 \%$ để thực hiện thí nghiệm tối ưu hóa.

\subsubsection{Xác định phạm vi giới hạn của tỷ lệ muối ăn}

Chúng tôi đã tiến hành thí nghiệm xác định thành phần gia vị cho sản phẩm thịt cừu sấy dẻo theo qui trình chế biến dự kiến và sơ bộ xác định giới hạn của tỷ lệ muối ăn thích hợp cho sản phẩm thịt cừu sấy dẻo là $3,2 \%$ đến $3,6 \%$.

\subsubsection{Thí nghiệm tối ưu hóa tỷ lệ sorbitol, glyc- erin, muối ăn}

Từ các thí nghiệm xác định phạm vi ảnh hưởng của các yếu tố thí nghiệm, giá trị mã hóa và ma trận của thí nghiệm tối ưu tỷ lệ sorbitol, glycerin và muối ăn được thể hiện trong Bảng 5 và 6 .

Bảng 5. Giá trị mã hóa các thông số thí nghiệm tối ưu tỷ lệ sorbitol, glycerin và muối ăn

\begin{tabular}{lccc}
\hline \multirow{2}{*}{ Biến độc lập } & \multicolumn{3}{c}{ Giá trị mã hóa } \\
\cline { 2 - 4 } & -1 & 0 & 1 \\
\hline $\mathrm{x}_{1}$ : Tỷ lệ sorbitol $(\%)$ & 3,5 & 4 & 4,5 \\
$\mathrm{x}_{2}$ : Tỷ lệ glycero $(\%)$ & 1,5 & 2 & 2,5 \\
$\mathrm{x}_{3}$ : Tỷ lệ muối ăn $(\%)$ & 3,2 & 3,4 & 3,6 \\
\hline
\end{tabular}

Kết quả thu được từ 15 thí nghiệm đã được xử lý bằng phần mềm thống kê $\mathrm{JMP}$, từ đó xác định được mối tương quan giữa các yếu tố tỷ lệ sorbitol, glycerin và muối ăn với hoạt độ nước của sản phẩm, đồng thời xây dựng được phương trình hồi quy và dự đoán các thông số của các yếu tố cho hoạt độ nước của sản phẩm thịt cừu sấy dẻo là tối ưu. Sự tương quan giữa hoạt độ nước sản phẩm của mô hình và thực tế được thể hiện trong Hình 6.

Giá trị $\mathrm{R}^{2}$ của mô hình là 0,98 ; cho thấy hoạt độ nước sản phẩm thực tế và mô hình có sự tương quan với nhau. Chúng tôi kết luận là phương trình hồi quy có mức độ tương thích khá cao, ở độ tin cậy 95\%. Qua xử lý thống kê, cho thấy tác động của tỷ lệ sorbitol, glycerol, muối ăn có ảnh hưởng quan trọng đến độ ẩm của sản phẩm có và có ý nghĩa thống kê $(P$ $<0,05)$. Sau khi loại bỏ những yếu tố không có ảnh hưởng quan trọng, chúng tôi có được phương trình hồi quy: $\mathrm{y}=0,691-0,039 \mathrm{x}_{1}+$ $0,0135 \mathrm{x}_{2}+0,0125 \mathrm{x}_{3}-0,02675 \mathrm{x}_{1} \mathrm{x}_{2}-0,01775 \mathrm{x}_{2} \mathrm{x}_{3}$ $+0,013875 x_{1}^{2}-0,028125 x_{2}^{2}+0,012375 x_{3}^{2}$. Trong đó: $\mathrm{y}$ là hoạt độ nước $(\mathrm{aw})$ của thịt cừu sấy dẻo $(\%), \mathrm{x}_{1}$ (tỷ lệ sorbitol), $\mathrm{x}_{2}$ (tỷ lệ glycerin) và $\mathrm{x}_{3}$ (tỷ lệ muối ăn).

Mô hình xác định được cho thấy hoạt độ nước của sản phẩm phụ thuộc, bị ảnh hưởng nhiều vào 


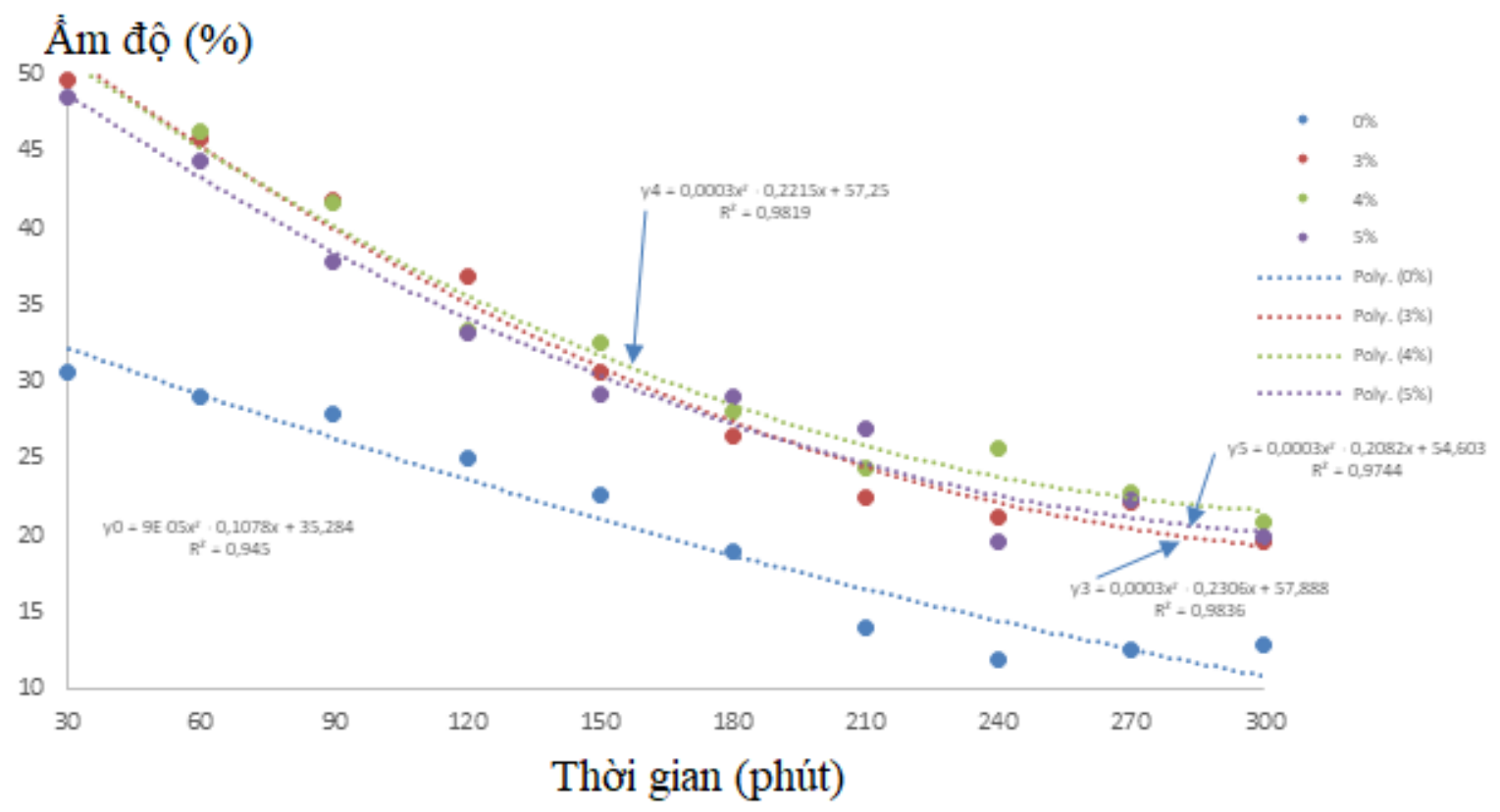

Hình 4. Biến thiên ẩm độ của sản phẩm theo thời gian sấy ứng với tỷ lệ sorbitol khác nhau.

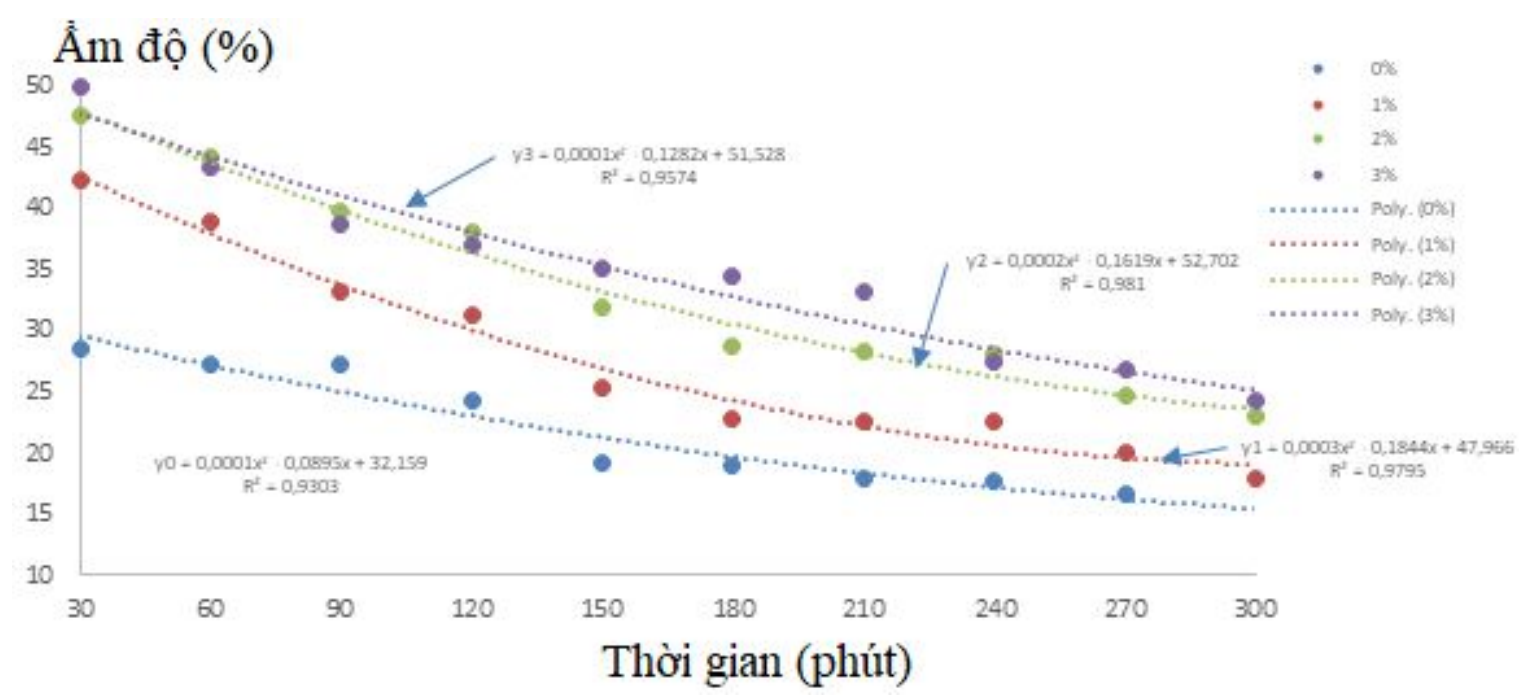

Hình 5. Biến thiên ẩm độ của sản phẩm theo thời gian sấy ứng với tỷ lệ glycerin khác nhau.

tỷ lệ sorbitol, glycerin, muối ăn, đúng với nhận định của Sikorski \& ctv. (1976); Shenouda (1980), muối ăn là một yếu tố ảnh hưởng đến hoạt độ nước của sản phẩm trong quá trình sấy, muối làm protein biến tính tạo thuận lợi cho sự khuếch tán của độ ẩm từ nguyên liệu trong quá trình sấy (Nketsia-Tabiri \& Sefa-Dedeh, 1995).

Dự đoán giá trị tối ưu của các yếu tố thí nghiệm: Sự tương tác của các yếu tố khảo sát (tỷ lệ sorbitol, glycerol, muối ăn) được biểu diễn qua đường đồng mức được thể hiện ở Hình 7 . Chúng tôi chọn được các tỷ lệ sorbitol, glycerol, muối ăn tối ưu cho quá trình sấy là 4,37\% sorbitol, 1,93\% glycerol và $3,4 \%$ muối ăn, sản phẩm có hoạt độ nước là 0,67 .

Kiểm chứng giá trị tối ưu từ mô hình thực 
Bảng 6. Ma trận của thí nghiệm tối ưu tỷ lệ sorbitol, glycerin và muối ăn

\begin{tabular}{cccccc}
\hline TT & Ma trận & Sorbitol (\%) & Glycerol (\%) & Muối (\%) & aw \\
\hline 1 & 0 & 4 & 2 & 3,4 & 0,685 \\
2 & 0 & 4 & 2 & 3,4 & 0,693 \\
3 & $+0-$ & 4,5 & 2 & 3,2 & 0,663 \\
4 & $0-+$ & 4 & 1,5 & 3,6 & 0,694 \\
5 & $0++$ & 4 & 2,5 & 3,6 & 0,69 \\
6 & $0+-$ & 4 & 2,5 & 3,2 & 0,692 \\
7 & $-0+$ & 3,5 & 2 & 3,6 & 0,749 \\
8 & $+0+$ & 4,5 & 2 & 3,6 & 0,702 \\
9 & 0 & 4 & 2 & 3,4 & 0,695 \\
10 & --0 & 3,5 & 1,5 & 3,4 & 0,682 \\
11 & -+0 & 3,5 & 2,5 & 3,4 & 0,758 \\
12 & $0--$ & 4 & 1,5 & 3,2 & 0,625 \\
13 & 0 & 4,5 & 2,5 & 3,4 & 0,618 \\
14 & $-0-$ & 3,5 & 2 & 3,2 & 0,755 \\
15 & +-0 & 4,5 & 1,5 & 3,4 & 0,649 \\
\hline
\end{tabular}

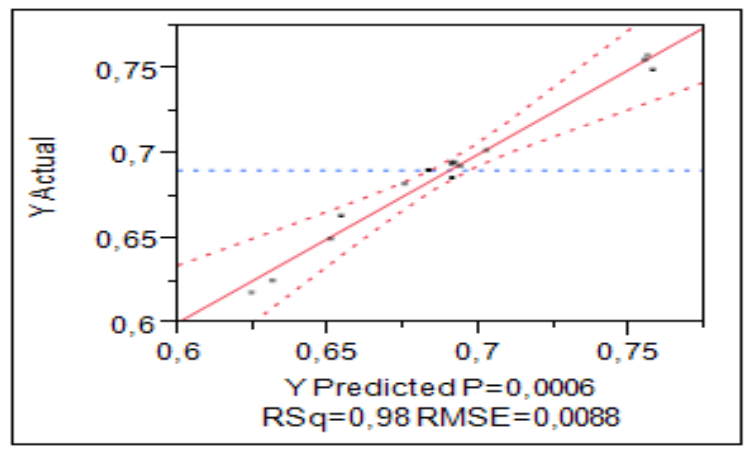

Hình 6. Biểu đồ tương quan giữa hoạt độ nước sản phẩm ứng với mô hình và thực tế.

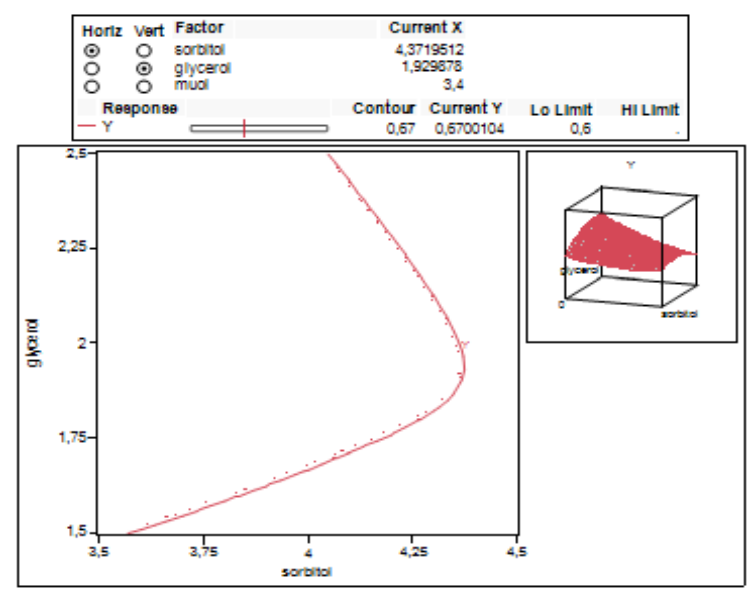

Hình 7. Đường đồng mức biểu diễn tương quan giữa hoạt độ nước thịt cừu sấy dẻo và tỷ lệ sorbitol, glycerol, muối ăn. nghiệm: Từ các tỷ lệ sorbitol, glycerol, muối ăn tối ưu của sản phẩm thịt cừu sấy dẻo được xác định bằng phương trình của mô hình bề mặt đáp ứng, chúng tôi tiến hành thực nghiệm để kiểm chứng lại các thông số tối ưu, chứng minh tính xác thực của mô hình. Chúng tôi thực nghiệm trên các thông số tối ưu với 3 lần lặp lại, lấy giá trị trung bình, kết quả được trình bày ở Bảng 7 và 8 .

Bảng 7. Kết quả kiểm chứng giá trị độ ẩm thực nghiệm của quá trình sấy thịt cừu

\begin{tabular}{cc}
\hline Tham số thống kê & $\begin{array}{c}\text { Hoạt độ nước sản } \\
\text { phẩm thực tế }\end{array}$ \\
\hline 1 & 0,655 \\
2 & 0,638 \\
3 & 0,649 \\
Hoạt độ nước & 0,647 \\
SD & 0,009 \\
\hline
\end{tabular}

Bảng 8. Kiểm chứng giá trị tối ưu từ mô hình bằng thực nghiệm

\begin{tabular}{lccc}
\hline \multirow{2}{*}{ Biến độc lập } & \multicolumn{2}{c}{ Điều kiện } \\
\cline { 3 - 4 } & Mô hình & Thực tế \\
\hline $\begin{array}{l}\text { Hoạt độ nước } \\
\text { phẩm }(\mathrm{aw})\end{array}$ & 0,670 & 0,647 \\
Độ lệch chuẩn $(\mathrm{SD})$ & 0 & 0,009 \\
\hline
\end{tabular}

Kết quả cho thấy hoạt độ sản phẩm thịt cừu sấy dẻo có sự khác biệt giữa mô hình và thực tế là $3,38 \%$ nhỏ hơn $5 \%$, nên mô hình có giá trị thực tiễn và có thể áp dụng vào thực tế sản xuất. 


\section{Kết Luận}

Thịt cừu sấy dẻo là một sản phẩm mới, các thông số kỹ thuật của qui trình sản xuất cần được nghiên cứu, trong đó quá trình sấy quyết định quan trọng đến chất lượng của sản phẩm. Kết quả nghiên cứu đã xác định được quá trình sấy tối ưu để áp dụng trong thực tế sản xuất, đó là:

Chế độ sấy tối ưu đưa vào sản xuất với nhiệt độ sấy $56^{0} \mathrm{C}$, thời gian sấy 210 phút ở tốc độ gió $0,24 \mathrm{~m} /$ giây.

Tỷ lệ sorbitol, glycerol, muối ăn tối ưu cho quá trình sấy là 4,37\% sorbitol, 1,93\% glycerol và $3,4 \%$ muối ăn.

\section{Tài Liệu Tham Khảo (References)}

Aranda, I. D., Casas, E. V., Peralta, E. K., \& Elauria, J. C. (2010). Drying janitor fish for feeds in Laguna lake to mitigate pollution potentials. Journal of Environmental Science and Management 13(2), 27-43.

Djendoubi, N., Boudhrioua, N., Bonazzi, C., \& Kechaou, N. (2009). Drying of sardine muscles: Experimental and mathematical investigations. Food and Bioproducts Processing 87, 115-123.

Flath, L. E., \& Diana, J. S. (1985). Seasonal energy dynamics of the alewife in Southeastern Lake Michigan. Transactions of the American Fisheries Society 114, 328-337.

Gallart-Jornet, L., Barat, J. M., Rustad, T., Erikson, U., Escriche, I., \& Fito, P. (2007). Influence of brine concentration on Atlantic salmon fillet salting. Journal of Food Engineering 80, 267-275.

Jittinandana, S., Kenney, P. B., Slider, S. D., \& Kiser, R. A. (2002). Effect of brine concentration and brining time on quality of smoked rainbow trout fillet. Journal of Food Science 67(6), 2095-2099.
Law, C. L., Chen, H. H. H., \& Mujumdar, A. S. (2014). Foods, materials, technologies and risks. Encyclopedia of Food Safety (156-167) - Vol. 3. Massachusetts, USA: Academic Press.

Nguyen, M. V., \& Tran, T. T. (2016). Effects of the control of water activity on dried fish made from snakehead fish farmed in Dong Thap province. Can Tho University Journal of Science 1, 92-97.

Nindo, C. I., \& Tang, J. (2007). Refractance window dehydration technology: A novel contact drying method. Drying Technology 25, 37-48.

Nketsia-Tabiri, J., \& Sefa-Dedeh, S. (1995). Optimization of process, conditions and quality of salted dried tilapia (Oreochromis miloticus) using response surfacemethodology. Journal of the Science of Food and Agriculture 69(1), 117-127.

Ofstad, R., Kidman S., \& Hermansson, A. M. (1996). Ultramicroscopical structures and liquid loss in heated cod (Gadus morhua) and salmon (Salmo salar) muscle. Journal of the Science of Food and Agriculture 72(3), 337-347.

Ortiz, J., Lemus-Mondaca, R., Vega-Gálvez, A., Ah-Hen, K., Puente-Diaz, L., Zura-Bravo, L., \& Aubourg, S. (2013). Influence of air-drying temperature on drying kinetics, colour, firmness and biochemical characteristics of Atlantic salmon (Salmo salar L.) fillets. Food Chemistry 139, 162 - 169.

Prachayawarakorn, S., Soponronnarit, S., Wetchacama, S., \& Jaisut, D. (2002). Desorption isotherms and drying characteristics of shrimp in superheated steam and hot air. Drying Technology 20, 669-684. 